\title{
COMPOSIÇÃO BOTÂNICA NA ÁREA DE INFLUÊNCIA DA COPA DE JENIPAPEIRO EM PASTAGENS NO ASSENTAMENTO BELO HORIZONTE I, SÃO DOMINGOS DO ARAGUAIA-PA
}

\author{
Ilmaione Keiza de Souza Oliveira ${ }^{1}$; Rosana Quaresma Maneschy ${ }^{2}$; Tatiane Pereira \\ Guimarães $^{3}$; Albinei Araújo de Castro ${ }^{4}$; Karolinny Carneiro Guerra Costa ${ }^{5}$ \\ ${ }^{1}$ Discente de Agronomia da UFPA - Campus de Marabá, Bolsista PIBIC/PARD, ilmaionekeiza@ hotmail.com \\ ${ }^{2}$ Eng. Agrônoma, DSc., Prof. a, da FCAM/UFPA, romaneschy@ufpa.br \\ ${ }^{3}$ Discente de Agronomia da UFPA - Campus de Marabá, Bolsista FAPESPA, tatianepg.ufpa@gmail.com \\ ${ }^{3}$ Discente de Agronomia da UFPA - Campus de Marabá, Bolsista PIBIC/PARD, karolinnycg.guerra@gmail.com \\ ${ }^{5}$ Discente de Agronomia da UFPA - Campus de Marabá, Bolsista FAPESPA, albinei_araujo@hotmail.com
}

\begin{abstract}
RESUMO: Os sistemas silvipastoris (SSP) do tipo "árvores dispersas nas pastagens" formados a partir do manejo da regeneração natural são indicados para reabilitação de áreas degradadas com baixo uso de insumos. Objetivou-se identificar as espécies arbóreas invasoras abaixo da copa do jenipapeiro (Genipa americana L.) para comparar com a riqueza e frequência das mesmas em pastagem aberta. $\mathrm{O}$ estudo foi realizado em três propriedades de agricultores familiares no assentamento rural "Belo Horizonte I" em São Domingos do Araguaia - PA. Utilizou-se uma amostragem pareada, com uma parcela controle de $4 \mathrm{~m}^{2}$ em pastagem aberta para cada parcela de igual tamanho, situado abaixo da copa da árvore. A copa do jenipapo propiciou um micro clima favorável à regeneração natural das espécies arbóreas: goiaba (Psidium guajava), ipê roxo (Tabebuia impetiginosa), mutamba lisa (Guazuma sp) e mutamba preta (G. ulmifolia). Concluiu-se que o jenipapo pode ser uma espécie com potencial para recuperação de áreas de pastagens degradadas facilitando o processo de sucessão e auxiliando na formação de SSP.
\end{abstract}

PALAVRAS-CHAVE: Genipa americana L., regeneração natural, sistema silvipastoril.

\section{BOTANICAL COMPOSITION FROM UNDER CANOPY THE GENIPAP IN PASTURES IN SETTLEMENT BELO HORIZONTE I, SÃO DOMINGOS DO ARAGUAIA-PA}

\begin{abstract}
The silvopastoral systems (SPS) of the type "dispersed trees in pasture" formed from the management of natural regeneration are indicated for reclamation of degraded with low input. This objective recorded the invasive tree species from under canopy the genipap (Genipa americana) and compared the richness and frequency of those species in open pastures. The study was conducted in three family farms in the rural settlement "Belo Horizonte I" in São Domingos do Araguaia - PA. A pared design was used, with a $4 \mathrm{~m}^{2}$ control plot in open pasture for each equally sized plot under the canopy of the tree. The genipap canopy provided a microclimate favorable to natural regeneration of tree species: Psidium guajava, Tabebuia impetiginosa, Guazuma sp and G. ulmifolia. It was concluded that the genipap may be a species with potential for recovery of degraded pasture areas by facilitating the succession process and helping in the formation of the SSP.
\end{abstract}

KEY-WORDS: Genipa americana L., natural regeneration, silvopastoral system. 


\section{INTRODUÇÃO}

Pesquisas realizadas em diversos países indicam a eficiência do componente arbóreo como incremento na produtividade pecuária (PEZO; IBRAHIM, 1999). Por isso, cada vez mais a comunidade científica tem recomendado o uso de sistemas silvipastoris (SSP) como alternativa sustentável para reabilitação de áreas de pastagens degradadas e/ou integração de sistemas tradicionais de produção praticados pelos agricultores. Por serem mais diversificados e com maior longevidade produtiva são considerados como uma alternativa para a recuperação de pastagens degradadas, sendo benéfica para o pasto, solo e aumentando da biodiversidade existente através da regeneração natural (FRANKE et al., 2001; PEZO; IBRAHIM, 1999).

Segundo Esquivel e Calle (2002) a composição da regeneração natural em área de pastagem está relacionada com as espécies arbóreas dispersas no piquete que podem facilitar a regeneração de certas espécies de árvores. Abaixo das copas de árvores tipicamente encontradas em piquetes na cordilheira ocidental na Colômbia foram identificadas tanto plantas forrageiras como espécies próprias de bosques secundários. Pesquisadores têm indicado a espécie frutífera jenipapo (Genipa americana L.) para o reflorestamento de áreas degradadas, devido as suas características florestal e também pela utilização dos seus frutos na produção de alimentos tanto para fauna como o homem, além de ser uma espécie medicinal (FERREIRA et al., 2007).

Com isso o estudo tem como objetivo identificar as espécies de plantas jovens e plântulas arbóreas ou arbustivas invasoras abaixo da copa de jenipapo e comparar a abundância de plântulas e frequência das mesmas em pastagens abertas. Isto visa contribuir com informações sobre a importância das árvores dispersas na pastagem devido ao processo de manejo da regeneração natural, em especial por seu vínculo com funções ecossistêmicas relacionadas com a manutenção da biodiversidade na paisagem rural.

\section{MATERIAL E MÉTODOS}

Esse estudo é uma ação do projeto de pesquisa "Regeneração natural de espécies arbóreas na pastagem como alternativa silvipastoril para a sustentabilidade da agricultura familiar no Sudeste do Pará" da Universidade Federal do Pará, Campus Marabá. O estudo foi desenvolvido no projeto de assentamento (P. A.) Belo Horizonte I, situado no km 30 da BR-153 no município de São Domingos do Araguaia, na microrregião de Marabá, sendo composto por aproximadamente 40 famílias. O clima local é de Afi no limite de transição para Awi com temperatura média de $28,0{ }^{\circ} \mathrm{C}$ (ALMEIDA, 2007), com solos do tipo latossolo vermelho amarelo distrófico e podzólico vermelho 
amarelo. Nas propriedades ocorre um predomínio de áreas de pastagens, com ausência de florestas primárias e baixa diversificação dos sistemas de produção.

Foram selecionados quatro piquetes, com a espécie jenipapo dispersa nas pastagens com pastejo ativo, com área média de 0,5 ha e com carga animal semelhante. Foram utilizados quatro indivíduos semelhantes através de avaliação silvicultural prévia, tendo como parâmetros médios: altura total de 10,25 $\mathrm{m}$, diâmetro a altura do peito de $0,26 \mathrm{~m} \mathrm{e}$ diâmetro de copa de 5,55 m. A avaliação foi realizada a partir de uma amostragem pareada, com parcelas de $4 \mathrm{~m}^{2}$, sendo uma abaixo da copa da árvore e uma em pastagem aberta (a $5 \mathrm{~m}$ de distância da parcela abaixo da copa da árvore) (ESQUIVEL; CALLE, 2002).

Todas as espécies foram identificadas, sendo que as espécies arbóreas foram classificadas em jovens (> $30 \mathrm{~cm}$ de altura) e plântulas $(<30 \mathrm{~cm}$ de altura). Foram calculadas as frequências absoluta (FA) e relativa (FR). A FA expressa à porcentagem de parcelas em que cada espécie ocorre (GREIG-SMITH, 1983) e a FR é a porcentagem de ocorrência de uma espécie em relação à soma das frequências totais de todas as espécies (MUELLER-DOMBOIS; ELLENBERG, 1974). Para a avaliação da similaridade entre as populações botânicas abaixo da copa e em pastagem aberta foi utilizado o Índice de Similaridade de Sorense, que é dado pela equação: IS $(\%)=(2 \mathrm{~A} / \mathrm{B}+\mathrm{C})$ $\mathrm{x} 100$, em que $\mathrm{A}=$ número de espécies comuns às duas áreas; $\mathrm{B}$ e $\mathrm{C}=$ número de espécies de cada uma das áreas (SORENSE, 1972).

\section{RESULTADOS E DISCUSSÃO}

Foram identificados 682 indivíduos distribuídos em 15 famílias botânicas e 29 espécies de regeneração natural abaixo da copa do jenipapo e em pastagem aberta (Tabela 1). As espécies mutamba preta, mutamba lisa e goiaba, que foram identificas em fase jovem abaixo da copa do jenipapo, provavelmente tiveram sua dispersão facilitada por aves e mamíferos, como equídeos e bovinos. Segundo Lopez et al. (1987) esses animais são considerados como agentes dispersores de sementes do tipo zoocórica (BRINA, 1998). A dispersão de ipê roxo pode ter sido facilitada pelo vento, pois as sementes são aladas - laminares, leves, com duas asas hialinas e curtas (FERREIRA; CHALUB; MUXFELDT, 2004).

Foram identificadas espécies frutíferas e madeireiras. A goiaba pode diversificar o sistema de produção do estabelecimento agrícola, pois segundo Franke (1999) é utilizada tanto na alimentação da fauna como humana, além de servir como cerca viva e pode fornecer sombra aos animais. Enquanto que a mutamba e o ipê roxo podem agregar valor ao estabelecimento já que, podem servir como adubo verde, cerca viva, forragem, 
lenha, carvão, planta medicinal e madeira comercial.

$\mathrm{O}$ índice de similaridade foi de $63,33 \%$ isso se deve ao numero de espécies herbáceas em comum nas parcelas. Porém o microclima diferenciado abaixo da copa da árvore favoreceu o aparecimento de plântulas das espécies arbóreas, pois o jenipapo possui copa grande e arredondada com ramos numerosos e fortes; com folhas simples medindo de 20 a $42 \mathrm{~cm}$ de comprimento por 9 a $16 \mathrm{~cm}$ de largura (PRANCE, 1975).

Tabela 1. Frequências absolutas (FA) e relativas (FR) de espécies vegetais abaixo da copa de Genipa americana $\mathrm{L}$. e em pastagem aberta $(\mathrm{N}=4)$.

\begin{tabular}{|c|c|c|c|c|c|}
\hline \multirow{2}{*}{ Família } & \multirow{2}{*}{ Nome cientifico (Nome comum) } & \multicolumn{2}{|c|}{ Abaixo da copa } & \multicolumn{2}{|c|}{ Pastagem aberta } \\
\hline & & FA\% & FR\% & FA\% & FR\% \\
\hline \multirow[t]{2}{*}{ ASTERACEAE } & Vernonia polyanthes Less. (Assa peixe) & 25 & 0,44 & & \\
\hline & Bidens rubifolia HBK (Picão) & & & 25 & 1,28 \\
\hline \multirow[t]{2}{*}{ BIGNONEACEAE } & Pyrostegia venusta Miers (Cipó de lagartixa) & 50 & 1,33 & & \\
\hline & Tabebuia impetiginosa (Mart. ex DC.) Standl. (Ipê roxo)* & 25 & 0,22 & & \\
\hline \multirow[t]{2}{*}{ CYPERACEAE } & Rhynchospora corymbosa (L.) Britton (Capim buriti) & 50 & 2,23 & 50 & 6,83 \\
\hline & Cyperus rotundus L. (Tiririca) & & & 75 & 6,41 \\
\hline DIOSCOREACEAE & Dioscorea alata L. (Inhame bravo) & & & 25 & 0,42 \\
\hline \multirow{4}{*}{ FABACEAE } & Calopogonium тисипoides Desv. (Calopogônio) & 75 & 2,67 & 50 & 11,96 \\
\hline & Desmodium ovalifolium (Prain) Wall. ex Merr (Desmódio) & 75 & 5,35 & 50 & 10,68 \\
\hline & Mimosa pudica L. (Mimosa) & 50 & 1,56 & 50 & 4,70 \\
\hline & Senna obtusifolia L. Irwin \& Barneby (Mata pasto) & 25 & 1,78 & 25 & 3,41 \\
\hline FABOIDEAE & Jacquemontia asarifolia L. B. Smith) (Jitirana) & 25 & 0,22 & & \\
\hline LAMIACEAE & Hyptis brevipes Poit. (Hortelãnzinha) & 25 & 1,11 & 25 & 10,68 \\
\hline LAURACEAE & Licaria rigida Kosterm (Louro amarelo)* & & & 25 & 0,42 \\
\hline \multirow[t]{3}{*}{ MALVACEAE } & Guazuma sp Mill (Mutamba lisa)* & 25 & 0,22 & & \\
\hline & Guazuma ulmifolia Lamarck (Mutamba preta)* & 25 & 0,44 & & \\
\hline & Sida rhombifolia L. (Malva relógio) & & & 25 & 4,27 \\
\hline MYRTACEAE & Psidium guajava Lineu (Goiaba)* & 50 & 0,22 & 25 & 1,70 \\
\hline PHYLANIHACEAE & Phyllanthus urinaria L. (Quebra pedra) & 25 & 2,00 & 25 & 2,13 \\
\hline \multirow[t]{6}{*}{ POACEAE } & Brachiaria brizantha cv. Marandú (Braquiarão) & 50 & 2,23 & 25 & 5,55 \\
\hline & Brachiaria decumbens cv. Basilisk (Braquiarinha) & 25 & 5,80 & 25 & 5,12 \\
\hline & Brachiaria humidicola (Rendle) Schweick (Quicuio) & 25 & 66,96 & & \\
\hline & Brachiaria mutica (Forsk.). Stapf. (Capim fino) & 25 & 1,78 & 25 & 5,12 \\
\hline & Panicum maximum cv. Mombaça (Mombaça) & 25 & 0,22 & 25 & 12,82 \\
\hline & Paspalum L. (Paspalhão) & 50 & 0,44 & 25 & 3,41 \\
\hline RUBIACEAE & Borreria verticillata (L.) G. Mey. (Vassoura de botão) & 25 & 0,44 & & \\
\hline \multirow[t]{2}{*}{ SOLANACEAE } & Solanum erianthum D. Don (Fumo bravo) & 25 & 0,89 & 25 & 2,13 \\
\hline & Solanum lycocarpum A. St.-Hil. (Berinjela) & & & 25 & 0,85 \\
\hline VERBENACEAE & Lantana camara L. (Chumbinho) & 50 & 1,11 & & \\
\hline
\end{tabular}

*Espécies arbóreas

\section{CONCLUSÕES}

O jenipapo é uma espécie com potencial para recuperação de áreas de pastagem degradadas sendo considerada facilitadora sucessional, uma vez que foi identificada maior diversidade de espécies arbóreas abaixo da copa dos indivíduos adultos dispersos na pastagem do que em pastagem aberta. 


\section{REFERÊNCIAS}

ALCÁZAR, C. C. Patrones de regeneración natural establecida de especies leñosas y su relación con aspectos estructurales, funcionales y de manejo en un agropaisaje mesoamericano. 2007. 196 f. Dissertação (Maestría en Manejo y Conservación de Bosques Tropicales y Biodiversidad) - Centro Agronómico Tropical de Investigación y Enseñanza. Turrialba, 2007.

ALMEIDA, M. F. de. Caracterização agrometeorológica do município de Marabá. 2007. 77 f. Trabalho de Conclusão de Curso (Agronomia) - Faculdade de Ciências Agrárias de Marabá, Universidade federal do Pará, Marabá, 2007.

BRINA, A. E. Aspectos da dinâmica da vegetação associada a afloramentos calcários na APA Carste de Lagoa Santa, MG. 1998. 105 f. Dissertação (Mestrado) Instituto de Ciências Biológicas, Universidade Federal de Minas Gerais. Belo Horizonte, 1998.

ESQUIVEL, M. J. S.; CALLE, Z. D. Arboles aislados en potreros como catalizadores de la sucesión en una localidad de la Cordillera Occidental Colombiana. Agroforestería em las Americas, v. 9, n. 33-34, p.43-47, 2002.

FERREIRA, L; CHALUB, D; MUXFELDT, R. Ipê amarelo-Tabebuia serratifolia (Vahl)
Nichols. Informativo Técnico Rede de

Sementes da Amazônia, n. 05, p. 2, 2004.

FERREIRA, W. R.; RANAL, M.; DORNELES, M. C.; SANTANA, D. G. Crescimento de mudas de Genipa americana L. Submetidas a condições de pré-semeadura. Revista Brasileira de Biociências, Porto Alegre, v. 5, p. 1026-1028, 2007.

FRANKE, I. L.; Principais usos e serviços de árvores e arbustos promissores que ocorrem em pastagens no Estado do Acre. Comunicado Técnico, Embrapa Acre, n. 106, p. 1-6, 1999.

FRANKE， I. L.; LUNZ, A. M. P.; VALENTIM, J. F.; AMARAL, E. F.; MIRANDA, E. M. Situação atual e potencial dos sistemas silvipastoris no Estado do Acre. In: CARVALHO, M.M.; ALVIM, M.J.; CARNEIRO, J.C. (Ed.). Sistemas agroflorestais pecuários: opções de sustentabilidade para áreas tropicais e subtropicais. Juiz de Fora: Embrapa-CNPGL; FAO, p.19-40, 2001.

GREIG-SMITH, P. Quantitative plant ecology. 3. ed. Oxford, England: Blackwel, 1983. 359 p.

LOPEZ, J. A.; LITTLE JUNIOR, E. L.; RITZ, G. F.; ROMBOLD, J. S.; HAHN, W. J. Arboles comunes del Paraguay: ñande 
yvyra mata kuera. Washington: Cuerpo de Paz, p. 425, 1987.

MUELLER-DOMBOIS, D.; ELLENBERG, H. A. Aims and methods of vegetation ecology. New York: Jonh Wiley, 1974. 545 p. PEZO, D.; IBRAHIM, M. Sistemas Silvopastoriles. Turrialba, Costa Rica: CATIE, 1999. 276 p.

PRANCE, G. T. Árvores de Manaus: Jenipapo. 17ed. Manaus: INPA, 1975. p. 223225.

SORENSE, T. A method of stablishing groups of equal amplitude in plant society based on similarity of species content. In: ODUN, E. P. (Ed.). Ecologia. 3 ed. México: Interamericana, 1972. $640 \mathrm{p}$. 